survey was related to biology. Most of the patients were treated with NSAI as an initial intent. A corticoids-based therapy was proposed to $1.4 \%$ of the patients and the corresponding specialist was a rheumatologist (98\%).

Conclusions: The de novo arthritis prevalence for GPs is less than $5 \%$ with the knee being the most affected joint. Most frequently, GP are faced with gout, rheumatoid arthritis and spondyloarthritis. The handling is in line with the corresponding guide of good clinical practice.

Disclosure of Interest: None declared

DOI: 10.1136/annrheumdis-2017-eular.2521

\section{AB1109 DOSE DE-ESCALATION IN A SPECIALIZED OUTPATIENT CLINIC ON BIOLOGICAL THERAPY: COST MINIMIZATION OBSERVATIONAL STUDY}

S. Manrique-Arija, I. Ureña, F.G. Jimenez-Nuñez, N. Mena-Vazquez, V. Coret, L. Cano-García, M.C. Ordoñez-Cañizares, C.M. Romero-Barco,

M. Rojas-Gimenez, C. Domic, C. Fuego, G. Diaz-Cordoves, A. Belmonte,

M.V. Irigoyen, A. Ponce, M. Rodriguez-Perez, A. Fernandez-Nebro. Department of Reumatology at the University Regional Hospital of Malaga (HRUM). Institute for Biomedical Research in Málaga (IBIMA). Malaga University., Malaga, Spain

Objectives: To estimate the annual cost in the use of biological therapy (BT) in patients with different rheumatic diseases when dose modifications are undertaken in daily clinical practice in a specialized outpatient clinic during 2016 and to compare the results with data obtained in 2013.

Methods: Design: Cost minimization observational study under conditions of clinical practice. Patients: Patients with different rheumatic diseases who come to a specialized outpatient clinic on BT in the Rheumatologic department at a tertiary Spanish hospital (with a tight follow-up) that had been treated with BT under reduced doses during 2016 were collected. Protocol: Reductions in treatment dose or dose frequency were established empirically and were carried out by their rheumatologist in those patients who were in remission (DAS $28<2,6$ ) for at least 6 months without steroids. Main outcome: Reduction of annual average cost in euros in BT used in patients who are in dose reduction in clinical practice in 2016. Secondary outcome:Differences in annual costs reduction in 2016 compared with 2013. The cost reduction was calculated by comparing the actual expenditure (after modifying treatment dose in clinical practice) with the theoretical costs (official price) in case you had not made the adjustment. Statistical analysis: Sample descriptive analysis. Reducing annual absolute costs and by treatment after tapering down doses in clinical practice in 2016 and the differences found between 2013 were calculated.

Results: During 2016, the dose of the BT of 168 patients (94 Subcutaneous BT and 74 intravenous BT) were modified in clinical practice after reaching clinical remission:mean of DAS $28($ mean $+S D)=2.31+0.76$ or BASDAl $($ mean $\pm S D)=2.15+1.39$ without radiographic progression. Most patients were women $(n=113 ; 67 \%)$ and had rheumatoid arthritis $(n=103 ; 62 \%)$ and the rest were distributed among: spondyloarthritis $(n=28 ; 17 \%)$, psoriatic arthritis $(n=22 ; 13 \%)$, juvenile idiopathic arthritis $(n=10 ; 5 \%)$ and Systemic Lupus Erithematosus $(n=5 ; 3 \%)$. No patients treated with certolizumab or anakinra was modified treatment doses. During this period, 5 patients discontinued BT ( 3 remissions and 2 minor adverse events). Table 1 shows the number of patients by type of BT and costs. The BT dose reduction in clinical practice during 2016 represented a saving of $676,501.67 €$ and a greater efficiency of treatments while in 2013, only 86 patients (30 etanercept, 15 adalimumab, 16 Infliximab (Remicade), 15 Tocilizumab IV and 55 Rituximab) had a modified dose of BT in clinical practice assuming a saving of 396,995.46€. The difference in the annual cost reductions in 2016 compared to 2013 meant a saving of $279.506,21 €$ more in the last year. Table 1 .

\begin{tabular}{ccccc}
\hline $\begin{array}{c}\text { Biological } \\
\text { Therapy }\end{array}$ & $\begin{array}{c}\text { Patients } \\
\text { with } \\
\text { reduced } \\
\text { doses }\end{array}$ & $\begin{array}{c}\text { Theoretical } \\
\text { Annual costs } \\
\text { (Label doses) }\end{array}$ & $\begin{array}{c}\text { Real Annual Costs } \\
\text { (Clinical practice } \\
\text { doses) }\end{array}$ & $\begin{array}{c}\text { Annual costs } \\
\text { reduction } \\
2016\end{array}$ \\
\hline Etanercept & 53 & $582,453.04$ & $317,649.69$ & $264,803.35$ \\
\hline Adalimumab & 28 & $343,186.48$ & $217,922.02$ & $125,264.46$ \\
\hline Golimumab & 3 & $32,297.46$ & $28,898.76$ & $3,398.70$ \\
\hline Tocilizumab sc & 9 & $109,755.36$ & $79,137.42$ & $30,617,94$ \\
\hline $\begin{array}{c}\text { Tocilizumab iv } \\
\text { Abatacept }\end{array}$ & 15 & $179,821.23$ & $136,803.11$ & $43,018.12$ \\
\hline $\begin{array}{c}\text { Infliximab } \\
\text { (Remicade) }\end{array}$ & 15 & $16,512.42$ & $17,410.64$ & 898.22 \\
\hline Rituximab & 44 & $286,410.96$ & $122,779.26$ & $163,631.7$ \\
\hline Total & 168 & $\mathbf{1 , 7 1 5 , 0 2 6 . 6 5}$ & $\mathbf{1 , 0 4 0 , 3 2 1 . 4 2}$ & $\mathbf{6 7 6 , 5 0 1 . 6 7}$ \\
\hline
\end{tabular}

Conclusions: In rheumatic diseases we may do a dose de-escalation of BT in patients who go into remission and therefore we could reduce the associated costs of BT and being more efficient with the treatments. We believe that it is important to create specialized outpatient clinics on BT where a tight-control management of these patients and an individualized treatment are carried out. Disclosure of Interest: None declared
DOI: 10.1136/annrheumdis-2017-eular.6220

\section{AB1110 WHAT CAN GOOGLE TRENDS CAN TELL US ABOUT A DISEASE? BIG DATA TRENDS ANALYSIS IN SYSTEMIC LUPUS ERYTHEMATOSUS}

S. Sciascia, M. Radin. Department of Clinical and Biological Sciences, Center of Research of Immunopathology and Rare Diseases-Coordinating Center of Piemonte and Valle d'Aosta Network for Rare Diseases, Torino, Italy

Background: "Infodemiology" and "infoveillance" are two recent terms created to describe a new developing approach for public health, based on Big Data monitoring and data mining, applicable to provide new insights into unmet needs, such as the epidemiology of an uncommon disease like Systemic Lupus Erythematosus (SLE)[1].

Analysing how people (including patients, researchers, physicians) search and navigate the Internet for health-related information, as well as how they communicate and share this information, can provide valuable insights into health-related behaviour of populations.

Objectives: In this study we aimed to investigate trends of Internet search volumes linked to SLE, on-going clinical trials and research developments associated to the disease, using Big Data monitoring and data mining. We also aimed to analyse peak-related information to investigate knowledge translation of novel therapies for SLE and the influence of media on health-related information seeking.

Methods: We performed a longitudinal analysis based on the large amount of data generated by Google Trends, scientific search tools (SCOPUS, Medline/Pubmed/ClinicalTrails.gov) considering "SLE", and "lupus" in a 5-year webbased research.

Results: We observed an overall higher distribution of search volumes from Google Trends in United States, South America, Canada, South Africa, Australia and Europe (mainly Italy, United Kingdom, Spain, France, Germany), showing a geographically heterogeneity in insight into health-related behaviour of the different populations towards SLE. Data from Medline/Pubmed, SCOPUS and ClinicalTrials.gov were also analysed in order to monitor public health relevant publications and on-going trials. When comparing these results to the distribution of search volumes of Google Trends, we observed an overall similar distribution of Big Data for United States and Europe, while South America, Canada, Australia and South Africa were less represented. We observed a misbalance between search volumes for Google Trends compared to Medline/Pubmed, SCOPUS and ClinicalTrials.gov in some areas, suggesting a recent and expanding interest on SLE-related health issues in some countries.

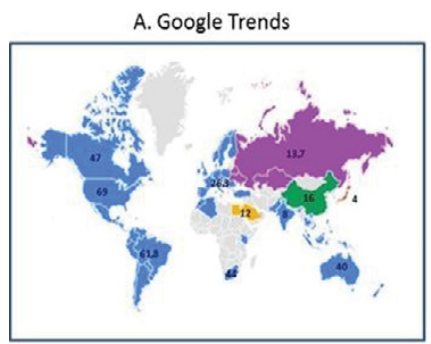

C. Pubmed

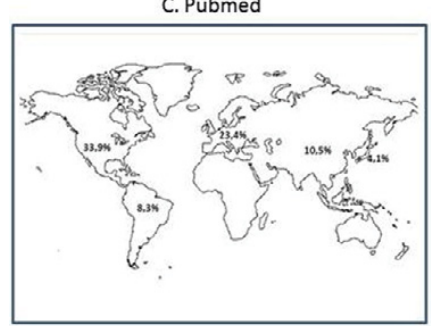

B. ClinicalTrials.gov

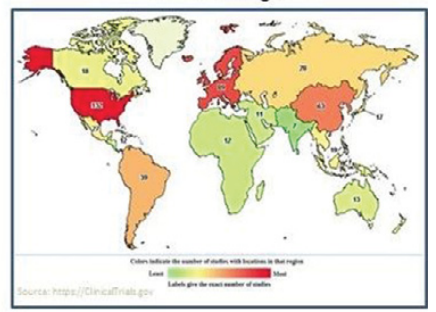

D. Scopus

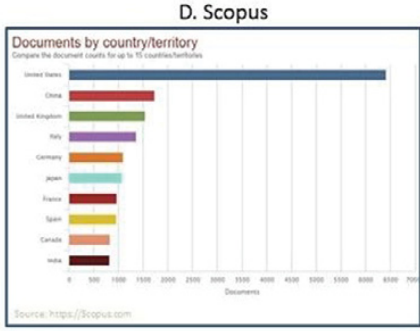

Figure1.: profile plots for relative search volumes. Profile plots show the relative search volumes, from January 2011 to January 2016, for 'Systemic Lupus Erythematosus' using Google Trends (Panel A), ClinicalTrials.gov (Panel B), PubMed (Panel C) and Scopus (Panel D). Date of search 16th October 2016.

Conclusions: We observed in some countries a misbalance between the search volumes generated by Google Trends and those analyzed through scientific search tools. This new approach, merging togheter informatics and epidemiology, is able to investigate health information seeking. In the near future it might give an estimate of the health-related demand and even of the health-related behaviour of patients with SLE.

References:

[1] Eysenbach G. Infodemiology and infoveillance: framework for an emerging set of public health informatics methods to analyze search, communication and publication behavior on the Internet. J Med Internet Res 2009;11:e11. doi:10.2196/jmir.1157. 
Disclosure of Interest: None declared

DOI: 10.1136/annrheumdis-2017-eular.1611

\section{AB1111 A PROSPECTIVE COHORT STUDY MEASURING COST-BENEFIT ANALYSIS OF THE OTAGO EXERCISE PROGRAMME IN COMMUNITY DWELLING ADULTS WITH RHEUMATOID ARTHRITIS}

S. Abdulrazaq ${ }^{1}$, T. O'Neill ${ }^{2}$, E.K. Stanmore ${ }^{3}$, J. Oldham ${ }^{1}$, D. Skelton ${ }^{4}$, M. Pilling ${ }^{5}$, B. Gannon ${ }^{1}$, C. Toddd ${ }^{1}{ }^{1}$ School of Nursing, Midwifery and Social Work and MAHSC; ${ }^{2}$ School of Medical Sciences; ${ }^{3}$ School of Nursing, University of Manchester, Manchester; ${ }^{4}$ University of Glasgow, Glasgow; ${ }^{5}$ University of Manchester, Manchester, United Kingdom

Background: Falls are one of the major health problems in adults with Rheumatoid Arthritis (RA). Interventions, such as the Otago Exercise Programme (OEP), can reduce falls in community dwelling adults by up to $35 \%$. The cost-benefits of such a programme in adults with RA have not been studied

Objectives: To determine healthcare cost of falls in adults with RA, and estimate whether it may be cost efficient to roll out the OEP to improve function and prevent falls in adults living with RA.

Methods: Patients with Rheumatoid Arthritis aged $\geq 18$ years were recruited from four rheumatology clinics across the Northwest of England. Participants were followed up for 1 year with monthly fall calendars, telephone calls and self-report questionnaires. Estimated medical cost of a fall-related injury incurred per-person were calculated and compared with OEP implemention costs to establish potential economic benefits.

Results: 535 patients were recruited and 598 falls were reported by 195 patients. Cumulative medical costs resulting from all injury leading to hospital services is $£ 374,354$ (US\$540,485). Average estimated cost per fall is $£ 1120$ (US\$1617). Estimated cost of implementing the OEP for 535 people is $£ 116,479$ (US\$168,504) or $£ 217.72$ (US\$314.34) per-person. Based on effectiveness of the OEP it can be estimated that out of the 598 falls, 209 falls would be prevented. This suggests that $£ 234,583$ (US $\$ 338,116$ ) savings could be made, a net benefit of $£ 118,104$ (US $\$ 170,623)$.

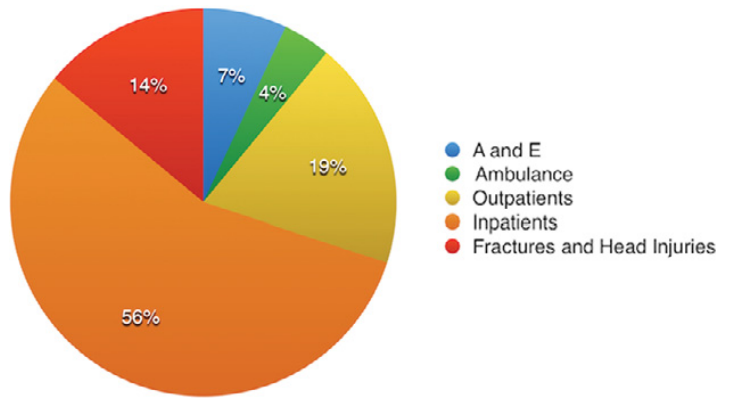

Figure 2. Chart showing spread of cost in health care costs

Conclusions: Implementation of the OEP programme for patients with RA has potentially significant economic benefits and should be considered for patients with the disease.

\section{References:}

[1] Stanmore EK, Oldham J, Skelton DA, O'Neill T, Pilling M, Campbell AJ, et al. Fall incidence and outcomes of falls in a prospective study of adults with rheumatoid arthritis. Arthritis Care Res (Hoboken). 2013;65(5):737-44.

[2] Stanmore EK, Oldham J, Skelton DA, O'Neill T, Pilling M, Campbell AJ, et al. Risk factors for falls in adults with rheumatoid arthritis: a prospective study. Arthritis Care Res (Hoboken). 2013:65(8):1251-8.

[3] Hayashibara M, Hagino H, Katagiri H, Okano T, Okada J, Teshima R. Incidence and risk factors of falling in ambulatory patients with rheumatoid arthritis: a prospective 1-year study. Osteoporos Int. 2010;21(11):1825-33.

[4] Gillespie LD, Robertson MC, Gillespie WJ, Sherrington C, Gates S, Clemson $\mathrm{LM}$, et al. Interventions for preventing falls in older people living in the community. Cochrane Database Syst Rev. 2012;9:CD007146.

[5] Gardner MM, Robertson MC, Campbell AJ. Exercise in preventing falls and fall related injuries in older people: a review of randomised controlled trials. British Journal of Sports Medicine. 2000;34(1):7-17.

[6] Robertson MC, Campbell AJ, Gardner MM, Devlin N. Preventing injuries in older people by preventing falls: a meta-analysis of individual-level data. J Am Geriatr Soc. 2002;50(5):905-11.

Acknowledgements: Special thanks to all the participants involved in the research and also the nursing staff who supported the data collection phase of the study at Manchester Academic Health Science Centre (MAHSC).

Disclosure of Interest: None declared

DOI: 10.1136/annrheumdis-2017-eular.1439

\section{AB1112 DATANETWORK RHEUMA 4.0 - REAL WORLD DATA FROM PRIVATE PRACTICE}

S. Kleinert ${ }^{1}$, F. Schuch ${ }^{1}$, S. Späthling-Mestekemper ${ }^{2}$, M. Feuchtenberger ${ }^{3}$, C. Kuhn ${ }^{4}$, M. Welcker ${ }^{5}$. ${ }^{1}$ Rheumatologie, Rheumatologische Schwerpunktpraxis, Erlangen; ${ }^{2}$ Rheumatologie, Rheumapraxis München-Pasing, München;

${ }^{3}$ Rheumatologie, Schwerpunktpraxis für Rheumatologie, Burghausen;

${ }^{4}$ Rheumatologie, Internistische Schwerpunktpraxis am Ludwigsplatz, Karlsruhe;

${ }^{5}$ Rheumatologie, MVZ für Rheumatologie Dr. Martin Welcker, Planegg, Germany

Background: The datanetwork Rheuma 4.0 (DNR_4.0) is a consortium of 5 internistic-rheumatologic specialized practices. Patient data that were collected routinely will be pooled pseudonymized (e.g. via RheumaDok) and will be made available to answer numerous healthcare- and scientific research questions.

Methods: The participating centres document the following data in specific rheumatologic data documentation systems (RheumaDok, Emil, DocuMed.rh). These data will be routed automatically to the data base of the DNR_4.0 via a prespecified interface and can be used for certain research areas:

Diagnosis (by rheumatologist $(R)$, anamnesis $(R)$, medication $(R)$, morning stiffness $(R$, patient $(P))$, scores like RADAI $(R, P)$, DAS28 (R), BASDAI (P), BASFI $(P)$, quality of life $(R, P)$. Also prespecified laboratory measures $(R)$ like ESR, CRP etc. can be collected automatically.

Patient reported Outcomes (PROs) that were entered via mobile applications like RheumaLive and AxSpALive can be collected in certain intervalls and be sent encrypted into the medical office data base.

The data entered by patients will be screened by the rheumatologist or nurse and will be stored in the underlying data base. Clinical data that are collected during regular F2F-appointments will be stored together with the PROs according to a specific period of time.

Results: The datanetwork Rheuma 4.0 (DNR_4.0) is an association of 5 internistic-rheumatologic specialized practices.

By the automated documentation of PROs (patient) and medical measures (rheumatologist) in an underlying data base, scientific and health care real worl data can be collected without extra workload or time requirements. These data are specific and different from data collected by other centres. In principal, the extension of the group to increase the number of participating centres is easily possible because the interface is an "open system". This allows to build an automised collecting, big and representative data base.

Now pooled data sets of 18.000 patients are available in the data base. In a first step, quality and the completeness of the existing data sets will be evaluated and the daily documentation routines will be described. Anonymised statistical analysis of the pooled data sets of the rheumatologic centres will allow to gain knowledge in respect to health care research of the own working group and external interested parties like research groups, sick funds, insurance companies and companies.

Conclusions: The german biologic registry Rabbit and the "Core documentation" data base deliver valid data about the safety and efficacy of rheumatologic medication. The datanetwork Rheuma 4.0 will make a valuable contribution especially in conjunction with apps of patient's self management like RheumaLive and AxSpALive - to health care research, therapeutic strategies and clinical questions from daily practice.

Acknowledgements: RheumaLive and AxSpALive werde developed by Starhealth $\mathrm{GmbH}$ on behalf of UCB Pharma $\mathrm{GmbH}$.

Disclosure of Interest: S. Kleinert Speakers bureau: UCB, F. Schuch Speakers bureau: UCB, S. Späthling-Mestekemper Speakers bureau: UCB, M. Feuchtenberger Speakers bureau: UCB, C. Kuhn: None declared, M. Welcker Speakers bureau: UCB

DOI: 10.1136/annrheumdis-2017-eular.5674

\section{AB1113 PATIENT PARTICIPATION IS CRUCIAL WHEN INTRODUCING NEW DEVICE TECHNOLOGIES IN THE MANAGEMENT OF CHRONIC ARTHRITIS: APPLYING THE PARKER MODEL, A QUALITATIVE 3-STEP APPROACH}

T.S. Jørgensen ${ }^{1}$, L. Klokker ${ }^{1}$, M. Skougaard ${ }^{1}$, H. Asmussen ${ }^{2,3}$, A. Lee ${ }^{4}$, I. Mountian ${ }^{5}$, H. Gudbergsen ${ }^{1}$, L.E. Kristensen ${ }^{1} .{ }^{1}$ The Parker Institute, Copenhagen University Hospital, Bispebjerg and Frederiksberg, Copenhagen; ${ }^{2}$ Communication IKH, Roskilde University, Roskilde; ${ }^{3}$ NATiON, Copenhagen; ${ }^{4}$ University of Southern Denmark, Odense, Denmark; ${ }^{5}$ UCB Pharma, Brussels, Belgium

Background: Patients' participation in design, development, and implementation of new device technologies is essential to ensure added value in patients' disease management.

Objectives: To explore the applicability and relevance of ava ${ }^{\circledR}$, an electromechanical device (e-Device), as an alternative method for subcutaneous administration of certolizumab pegol.

Methods: The Parker Model is an innovative 3-step qualitative research approach, which combined concept mapping (CM), participatory design (PD), and stakeholder evaluation (SE) to evaluate the e-Device (Figure). CM was applied through workshops, with the participation of patients, using a structured group process focusing on relevant themes to identify issues and concerns with the e-Device. Patients used this information in a series of iterative PD sessions; patients participated in 3 interactive sessions to create a personal e-Device prototype in 